\title{
Inspiratory Muscle Training Versus Diaphragmatic Breathing Exercise on Maximal Inspiratory Pressure and Blood Gases on Interstitial Pulmonary Fibrosis
}

\author{
ESRAA N. SAID, M.Sc.*; AWNY F. RAHMY, Ph.D.*,***; KHALED HALEMA, M.D.** and \\ MOHAMED SHENDY, Ph.D.* \\ The Department of Cardiovascular/Respiratory Disorder and Geriatrics, Faculty of Physical Therapy, Cairo University*, \\ Dean of Faculty of Physical Therapy, Pharos University, Alexandria*** and Department of Chest, Faculty of Medicine, \\ Al-Azhar University**
}

\begin{abstract}
Background: The work is done at El-Hussien Hospital in last January.

Aim of Study: To compare between the different effect of inspiratory muscle training and resistive diaphragmatic breathing on maximum inspiratory pressure and blood gases in patients with interstitial pulmonary fibrosis.
\end{abstract}

Material and Methods: Measuring maximal inspiratory pressure and measuring blood gases. Thirty patients (13 males and 17 females) with interstitial pulmonary fibrosis were selected from El-Hussien Hospital from 2017-2018. Their ages range from 50 to 60 years old. Patients were participated in physical therapy program for eight weeks, patients are assigned into two groups (A-B) equally in number. Group (A): ( 7 males and 8 females) received inspiratory muscle trainer for deep inspiratory exercise for 8 weeks 3 sessions per week. Group (B): (6 males and 9 females) received resistive diaphragmatic exercise for 8 weeks 3 sessions per week.

Results: Result showed that using inspiratory muscle training was more effective and fruitful than diaphragmatic breathing exercise on maximal inspiratory pressure and blood gases in interstitial pulmonary fibrosis as evidenced by significant increase in measuring maximum inspiratory pressure and blood gases.

Conclusion: Inspiratory muscle trainer is more effective than diaphragmatic breathing in increasing maximal inspiratory pressure and blood gases in interstitial pulmonary fibrosis.

Key Words: Inspiratory muscle training - Diaphragmatic breathing - Maximum inspiratory pressure Blood gases.

\section{Introduction}

INTERSTITIAL lung disease (ILD) includes a large number of conditions that are characterized

Correspondence to: Dr. Esraa N. Said, The Department of Cardiovascular/Respiratory Disorder and Geriatrics, Faculty of Physical Therapy, Cairo University by inflammation or fibrosis of the pulmonary parenchyma. ILD can occur due to a number of specific causes or may be classified as an idiopathic interstitial pneumonia (IIP), a group of well-defined ILDs that lack a clear predisposing factor or underlying pathophysiology [1].

Accurate classification of ILD requires a multidisciplinary approach that incorporates input from an experienced respirologist, chest radiologist and lung pathologist. Despite this effort, a large number of patients cannot be provided a confident ILD diagnosis, and are instead assigned a label of 'unclassifiable ILD'. This is particularly common in patients with fibrotic ILD, with a differential diagnosis that primarily includes idiopathic pulmonary fibrosis (IPF), chronic hypersensitivity pneumonitis (HP), idiopathic nonspecific interstitial pneumonia (NSIP) and connective tissue disease associated-ILD (CTD-ILD) [2].

Unclassifiable ILD represents a heterogeneous collection of undiagnosed fibrotic ILDs, and patients therefore have clinical features typical of IPF and other non-IPF ILDs (i.e. chronic hypersensitivity pneumonitis (HP), idiopathic nonspecific interstitial pneumonia (NSIP), and connective tissue interstitial lung disease (CTD-ILD). These common features include sub-acute onset of dyspnea, dry cough, auscultator crackles and the absence of clear exposures or features of autoimmune disease [3].

\section{Material and Methods}

In this study, the patients were randomly assigned into two equal groups (15 patients of each 
group) (study and control groups). Group (A): The study received inspiratory muscle training for deep inspiratory exercise for 8 weeks 3 sessions per week. Group (B): The controlled group received resistive diaphragmatic exercise for 8 weeks 3 sessions per week.

\section{Inclusive criteria included:}

Patients were of both sexes (males and females). Age of the patients ranged from 50 to 60 years.

\section{Exclusive criteria included:}

Any medical condition that had been contraindicated to exercise (e.g. General myopathy, bone deformity in spine and lower limb).

- Uncontrolled hypertension, cardiac conditions, psychiatric condition.

- Cognitive dysfunction.

- Addict patients.

- Unwilling to participate in the exercise program as defined by the protocol.

\section{Ethics:}

The protocol of this study was approved by the Ethical Committees of the Faculty of Physical Therapy (Cairo University. Egypt). Every patient applied informed consent before starting the study. All participants were informed about the nature and the effect of the treatment and measurement devices. The patients were also instructed to report any side effects during the treatment sessions.

\section{Measurements:}

\section{A- Evaluative procedures (initial evaluation):}

1- Each patient will receive full explanation of the objectives of the study, demonstration on equipments and procedures. Those patients who agreed to participate in the study will be signed an informed consent for participation.

2- Data concerning each subject characteristics will be collected in the first session including height and weight.

3- Maximum inspiratory pressure will be measured (as an initial evaluation) for each subject.

4- Arterial blood gases will be measured from a blood sample.

5- Calibration of instruments will be performed before each session.

\section{Assessment of ventilatory functions:}

The patient will be instructed how to perform spirometer as follow:

- Basically, he will take in a deep breath and blow into a mouthpiece attached to the spirometer.
- He will blow out as hard and as fast as he can until his lungs feel absolutely empty.

- He will be asked to repeat the test several more times until there are two to three good efforts. $\mathrm{He}$ will be coached and encouraged to do his best during the test. A good effort during the test is important to get good results.

- A computerized sensor (which is part of the spirometer) calculates and graphs the results. The results demonstrate a person's air flow rates or the volume forced out within the first second.

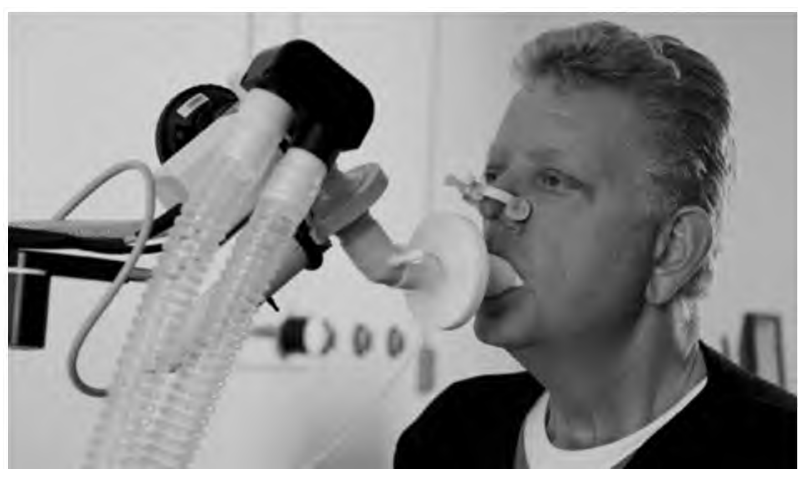

Fig. (1): Patient is using spirometer.

B- Treatment procedure:

1- Group (A): Each patient will receive inspiratory muscle training (threshold inspiratory muscle training device) in addition to conventional chest physiotherapy and medications.

Starting resistance:

The patients started breathing at a resistance equal to $30 \%$ of their maximal inspiratory pressure (MIP), measured at baseline.

Session duration: 20 minutes.

Frequency: One session for 3 days per week for 8 weeks consecutively under supervision.

\section{Incrementing the training load:}

The resistance will be increased incrementally, based on the rate of perceived exertion (RPE) scored by the patient on the Borg Scale. If the RPE was less than 5, the resistance of the inspiratory threshold trainer was increased incrementally by $2 \mathrm{cmH}_{2} \mathrm{O}$. The resistance will not change if the level of perceived exertion was rated from 6 to 8 , and the resistance will be decreased by 1 to $2 \mathrm{cmH}_{2} \mathrm{O}$ if the level of perceived exertion was rated 9 or 10 , then the load will be increased rapidly over the first 7 days up to $60-80 \%$ of baseline MIP.

2- Group (B): Diaphragmatic breathing. 
Breathing helps strengthen the diaphragm and the abdominal muscles, allowing more air to move in and out of your lungs without tiring the chest muscles.

\section{Progressive resistive exercises, with weights:}

After the placing the patient in supine, the therapist places a diaphragm weight pan over the epigastric region, without the pan resting on the ribs which can prevent full excursion. The amount of weight used as resistance should allow the epigastric rise to be the same as before the weight is applied. If the diaphragm is innervated, 5 pound weights can usually be used at first. When the patient can maintain a coordinated, unaltered breathing pattern for 15 minutes, with full epigastric rise and without substituting the sternocleidomastoid muscles, the weight can be increased until the patient's strength reaches an acceptable plateau, such as vital capacity remaining the same in a subsequent evaluation, or the patient being able to tolerate full activity with early signs of fatigue.

\section{Statistical analysis:}

Descriptive statistics and $t$-test were conducted for comparison of subject characteristics between both groups. $t$-test was conducted to compare mean values of regarding $\mathrm{MIP}, \mathrm{PaO}_{2}, \mathrm{PaCO}_{2}, \mathrm{HCO}_{3}$ and $\mathrm{pH}$ between both groups; and paired $t$-test was conducted to compare between pre and post treatment mean values of the measured variables in each group. The level of significance for all statistical tests was set at $p<0.05$. All statistical tests were performed through the statistical package for social sciences (SPSS) version 19 for windows (IBM SPSS, Chicago, IL, USA).

\section{Results}

\section{Subject characteristics:}

Table (1) showed the mean \pm SD age, weight, height and BMI of group A and B. There was no significant difference between both groups in the subject characteristics $(p<0.05)$.

\section{Within group comparison:}

There was a significant increase in MIP and $\mathrm{PaO}_{2}$ post treatment in group $\mathrm{A}$ compared with that pretreatment $(p=0.0001)$ with the percent of increase in MIP and $\mathrm{PaO}_{2}$ were 18.56 and $20.97 \%$ respectively. There was a significant decrease in $\mathrm{PaCO}_{2}, \mathrm{HCO}_{3}$ and $\mathrm{pH}$ post treatment compared with that pretreatment $(p>0.01)$. The percent of decrease in $\mathrm{PaCO}_{2}, \mathrm{HCO}_{3}$ and $\mathrm{pH}$ were 17.97, 2.14 and 0.53 respectively (Table 2 ).

Regarding group $\mathrm{B}$, there was a significant increase in MIP and $\mathrm{PaO}_{2}$ post treatment compared with that pretreatment $(p=0.0001)$ with the percent of increase in MIP and $\mathrm{PaO}_{2}$ were 6.44 and $6.33 \%$ respectively. There was a significant decrease in $\mathrm{PaCO}_{2}, \mathrm{HCO}_{3}$ and $\mathrm{pH}$ post treatment compared with that pretreatment $(p>0.05)$. The percent of decrease in $\mathrm{PaCO}_{2}, \mathrm{HCO}_{3}$ and $\mathrm{pH}$ were 8, 3.0, and 0.4 respectively (Table 2 ).

\section{Comparison between groups:}

There was no significant difference between both groups in all variables pre-treatment $(p>0.05)$. Comparison between groups post treatment revealed a significant increase in MIP and $\mathrm{PaO}_{2}$ of group A compared with that of group B $(p>0.05)$ and a significant decrease in $\mathrm{PaCO}_{2}$ of group A compared with that of group B $(p>0.05)$. However, there was no significant difference in $\mathrm{HCO}_{3}$ and $\mathrm{pH}$ between groups post treatment $(p<0.05)$ (Table 3$)$.

Table (1): Comparison of subject characteristics between group A and B.

\begin{tabular}{|c|c|c|c|c|c|}
\hline & \multicolumn{2}{|c|}{$\mathrm{X} \pm \mathrm{SD}$} & \multirow{2}{*}{ MD } & \multirow{2}{*}{$t$-value } & \multirow{2}{*}{$p$-value } \\
\hline & Group A & Group B & & & \\
\hline Age (years) & $55.6 \pm 3.26$ & $55.2 \pm 3.27$ & 0.4 & 0.33 & $0.74 *$ \\
\hline Weight (kg) & $84 \pm 8.51$ & $86.66 \pm 6.52$ & -2.66 & -0.96 & $0.34 *$ \\
\hline Height $(\mathrm{cm})$ & $166.2 \pm 9.93$ & $167.66 \pm 3.63$ & -1.46 & -0.53 & $0.59 *$ \\
\hline BMI $\left(\mathrm{kg} / \mathrm{m}^{2}\right)$ & $30.56 \pm 3.59$ & $30.85 \pm 2.46$ & -0.29 & -0.25 & $0.8^{*}$ \\
\hline $\begin{array}{l}X \quad: \text { Mean. } \\
\text { SD : Standard d } \\
\text { MD: Mean diffe } \\
p \text {-value: Probabi } \\
* \text { : Non-significa }\end{array}$ & & & & & \\
\hline
\end{tabular}


Table (2): Comparison of MIP, $\mathrm{PaO}_{2}, \mathrm{PaCO}_{2}, \mathrm{HCO}_{3}$ and $\mathrm{pH}$ between pre and post treatment in group $\mathrm{A}$ and $\mathrm{B}$.

\begin{tabular}{|c|c|c|c|c|c|c|}
\hline & \multicolumn{2}{|c|}{$\mathrm{X} \pm \mathrm{SD}$} & \multirow{2}{*}{ MD } & \multirow{2}{*}{$\begin{array}{c}\% \text { of } \\
\text { change }\end{array}$} & \multirow{2}{*}{$t$-value } & \multirow{2}{*}{$p$-value } \\
\hline & Pre treatment & Post treatment & & & & \\
\hline \multicolumn{7}{|l|}{ Group A: } \\
\hline $\operatorname{MIP}\left(\mathrm{cmH}_{2} \mathrm{O}\right)$ & $61.62 \pm 7.74$ & $73.06 \pm 6.77$ & -11.44 & 18.56 & -16.75 & $0.0001 * *$ \\
\hline $\mathrm{PaO}_{2}(\%)$ & $54.4 \pm 9.48$ & $65.81 \pm 7.88$ & -11.41 & 20.97 & -12.22 & $0.0001 * *$ \\
\hline $\mathrm{PaCO}_{2}(\mathrm{mmHg})$ & $37.95 \pm 4.13$ & $31.13 \pm 3.65$ & 6.82 & 17.97 & 25.49 & $0.0001 * *$ \\
\hline $\mathrm{HCO}_{3}(\mathrm{mmol} / \mathrm{l})$ & $29.37 \pm 4.56$ & $28.74 \pm 4.62$ & 0.63 & 2.14 & 5.22 & $0.0001 * *$ \\
\hline $\mathrm{pH}($ mole/l) & $7.48 \pm 0.04$ & $7.44 \pm 0.04$ & 0.04 & 0.53 & 3.13 & $0.007 *$ \\
\hline \multicolumn{7}{|l|}{ Group B: } \\
\hline $\operatorname{MIP}\left(\mathrm{cmH}_{2} \mathrm{O}\right)$ & $62.84 \pm 7.22$ & $66.89 \pm 7.3$ & -4.05 & 6.44 & -9.29 & $0.0001^{* *}$ \\
\hline $\mathrm{PaO}_{2}(\%)$ & $55.88 \pm 5.61$ & $59.42 \pm 6.09$ & -3.54 & 6.33 & -13.09 & $0.0001 * *$ \\
\hline $\mathrm{PaCO}_{2}(\mathrm{mmHg})$ & $36.86 \pm 3.34$ & $33.91 \pm 3.15$ & 2.95 & 8 & 8.56 & $0.0001 * *$ \\
\hline $\mathrm{HCO}_{3}(\mathrm{mmol} / \mathrm{l})$ & $27.78 \pm 3.29$ & $26.92 \pm 3.53$ & 0.86 & 3.09 & 4.69 & $0.0001 * *$ \\
\hline $\mathrm{pH}(\mathrm{mole} / \mathrm{l})$ & $7.49 \pm 0.02$ & $7.46 \pm 0.04$ & 0.03 & 0.4 & 2.25 & $0.04 * *$ \\
\hline
\end{tabular}

X: Mean. SD: Standard deviation. MD: Mean difference. $p$-value: Probability value. **: Significant.

Table (3): Comparison of MIP, $\mathrm{PaO}_{2}, \mathrm{PaCO}_{2}, \mathrm{HCO}_{3}$ and $\mathrm{pH}$ between group $\mathrm{A}$ and $\mathrm{B}$.

\begin{tabular}{|c|c|c|c|c|c|}
\hline & \multicolumn{2}{|c|}{$\mathrm{X} \pm \mathrm{SD}$} & \multirow{2}{*}{ MD } & \multirow{2}{*}{$t$-value } & \multirow{2}{*}{$p$-value } \\
\hline & Group A & Group B & & & \\
\hline \multicolumn{6}{|l|}{ Pre treatment: } \\
\hline $\mathrm{MIP}\left(\mathrm{cmH}_{2} \mathrm{O}\right)$ & $61.62 \pm 7.74$ & $62.84 \pm 7.22$ & -1.22 & -0.44 & $0.65^{*}$ \\
\hline $\mathrm{PaO}_{2}(\%)$ & $54.4 \pm 9.48$ & $55.88 \pm 5.61$ & -1.48 & -0.52 & $0.6^{*}$ \\
\hline $\mathrm{PaCO}_{2}(\mathrm{mmHg})$ & $37.95 \pm 4.13$ & $36.86 \pm 3.34$ & 1.09 & 0.79 & $0.43^{*}$ \\
\hline $\mathrm{HCO}_{3}(\mathrm{mmol} / \mathrm{l})$ & $29.37 \pm 4.56$ & $27.78 \pm 3.29$ & 1.09 & 0.28 & $0.28 *$ \\
\hline $\mathrm{pH}(\mathrm{mole} / \mathrm{l})$ & $7.48 \pm 0.04$ & $7.49 \pm 0.02$ & -0.01 & -0.77 & $0.44^{*}$ \\
\hline \multicolumn{6}{|l|}{ Post treatment: } \\
\hline $\mathrm{MIP}\left(\mathrm{cmH}_{2} \mathrm{O}\right)$ & $73.06 \pm 6.77$ & $66.89 \pm 7.3$ & 6.17 & 2.39 & $0.02 * *$ \\
\hline $\mathrm{PaO}_{2}(\%)$ & $65.81 \pm 7.88$ & $59.42 \pm 6.09$ & 6.39 & 2.48 & $0.01 * *$ \\
\hline $\mathrm{PaCO}_{2}(\mathrm{mmHg})$ & $31.13 \pm 3.65$ & $33.91 \pm 3.15$ & -2.78 & -2.22 & $0.03 * *$ \\
\hline $\mathrm{HCO}_{3}(\mathrm{mmol} / \mathrm{l})$ & $28.74 \pm 4.62$ & $26.92 \pm 3.53$ & 1.82 & 1.2 & $0.23^{*}$ \\
\hline $\mathrm{pH}(\mathrm{mole} / \mathrm{l})$ & $7.44 \pm 0.04$ & $7.46 \pm 0.04$ & -0.02 & -1.24 & $0.22 *$ \\
\hline $\begin{array}{l}\text { lean. } \\
\text { tandard devi }\end{array}$ & $\begin{array}{l}\text { MD: Me } \\
p \text {-value: }\end{array}$ & alue. & nifi & & \\
\hline
\end{tabular}

\section{Discussion}

Idiopathic pulmonary fibrosis (IPF), the most common form of the idiopathic interstitial pneumonias, is a chronic, progressive, irreversible, and usually lethal lung disease of unknown cause. IPF occurs in middle-aged and elderly adults (median age at diagnosis 66 years, range $55-75$ years), is limited to the lungs, and is associated with a histopathological or radiological pattern typical of usual interstitial pneumonia [4].

Patients with IPF usually seek medical attention because they suffer chronic and progressive exertional dyspnea and cough. Bibasilar inspiratory crackles are heard on chest auscultation and frequently finger clubbing is found. The natural history of IPF has been characterized as a steady or slowly progressive lung disorder, and most patients follow this pattern. However, recent findings indicate that
IPF is a heterogeneous disease and new clinical phenotypes with distinct patterns of survival are being described. The pathogenic mechanisms are unclear, but a growing body of evidence indicates that the disease is the result of an abnormal behavior of the alveolar epithelial cells that provoke the migration, proliferation, and activation of mesenchymal cells, with the formation of fibroblast and myofibroblast foci. Activated myofibroblasts secrete exaggerated amounts of extracellular matrix molecules with the subsequent destruction of the lung architecture [5].

IPF has a heterogeneous clinical course, and patients have a median survival of 2.5-3.5 years after diagnosis. Clinical phenotypes with distinct patterns of comorbidities and survival are being defined. Worse prognosis is associated with old age ( $>70$ years of age), smoking history, low bodymass index, severe physiological impairment, large 
radiological extent of disease and pulmonary hypertension [6].

Respiratory muscle training Recent studies in patients with IPF have shown natural adaptations of the diaphragm at cellular (increased proportion of type I fibers) and subcellular (shortening of the sarcomeres and increased concentration of mitochondria) levels contributing to greater resistance to fatigue and to better functional muscle behaviour [7].

Diaphragmatic breathing improves pulmonary ventilation, mainly to the basal segments of the lung. An increase in the displacement of the abdominal compartment compared to rest (with 60\% contribution to $\mathrm{Vcw}$ ) was observed during this exercise. Therefore, this exercise can improve the contribution of the AB to the $\mathrm{Vcw}$, possibly contributing to air distribution to the basal segments of the lungs [8].

In patients with IPF, breathing techniques aim at relieving dyspnea by: (1) increasing strength and endurance of the respiratory muscles; (2) optimizing the pattern of thoracoabdominal motion; and (3) reducing dynamic hyperinflation of the rib cage and improving gas exchange. It is believed that when respiratory muscle effort (ratio of the actual inspiratory pressure over the maximal inspiratory pressure, PI/Pimax) exceeds a critical level, breathing is perceived as unpleasant. 3 By improving respiratory muscle function or reducing inspiratory load the aim is to reduce the relative load on the muscles muscles might enhance their strength and/or endurance capacity and thus ventilator capacity, relieve symptoms and improve exercise performance [9].

Results of this study concerning the efficacy inspiratory muscle trainer on maximum inspiratory pressure and blood gases and the non-efficacy of diaphragmatic resistive breathing exercise on maximum inspiratory pressure and blood gases in IPF that observed and recorded by Hansen and Wasserman [10]; Jastrzebski et al. [11]; Osamu et al., [12]; Huppmann et al., [13]; Florian et al., [14]; Ignacio et al., [15]; Anne and Nicolino [16]; Nishiyama et al., [17].

Hansen and Wasserman [10] reported a significant increase in the $\mathrm{PaO}_{2}$ during exercise using inspiratory muscle training in patients with IPF. They reviewed the exercise studies in a group of 42 patients with ILD without musculoskeletal disease, obstructive disease, other restrictive disease, or cardiovascular disease. As expected, peak exercise $\mathrm{PaO}_{2}$ correlated inversely with peak ex- ercise $\mathrm{PaO}_{2}$ illustrating a gas exchange abnormality characterized by low VA/Q mismatch.

Jastrzebski et al., [11] reported a positive correlation between the arterial blood gas level and exercising by using inspiratory muscle trainer. They found that patients improved the $\mathrm{PaO}_{2}$ levels, and that the FEV 1 was positively correlated with inspiratory muscle training as well.

Osamu et al., [12] reported that there is an efficacy of pulmonary rehabilitation in IPF patients just like the efficacy of pulmonary rehabilitation in COPD patients in many clinical studies, and rehabilitation programmes have been widely adopted for treating patients with COPD.

Osamu et al., [12] reported that in IPF patients, there was a significant improvement in functional exercise capacity assessed by a 6-min walking test and in the healthrelated quality of life score, but not in the BDI score. Although these results suggest that it is difficult to improve dyspnoea ratings in IPF patients, the improvement in the 6-min walking test seems comparable with that of patients with COPD as previously reported.

Huppmann et al., [13] found significant and clinically relevant improvements in functional exercise capacity (increase in 6MWD $46 \pm 3 \mathrm{~m}$ ) evaluated 402 patients with ILD (including 202 IPF patients, mean $\mathrm{VC}=53 \%$ predicted) following a 4-week inpatient PR program. Score $+10 \pm 1$ points; both $p<0.001)$. These benefits were independent of the underlying disease (IPF, cryptogenic organizing pneumonia, hypersensitivity pneumonitis, sarcoidosis, and others).

Florian et al., [14] found that the blood gases and maximum inspiratory pressure of patients on the active list for lung transplant suffering of IPF improved following a 36-session rehabilitation program (90min, three times per week). The physiotherapy consisted of inspiratory muscle training exercises, inspiratory resistive exercising, and aerobic exercise on a treadmill. The preoperative rehabilitation program also involved a psychiatric evaluation, nutritional counseling, social assistance, and educational lectures.

Ignacio et al., [15] found that pulmonary rehabilitation using inspiratory muscle trainer benefits patients with IPF by enhancing their levels of blood gases while in the program and by significantly reducing the disease's symptom burden. Such results should spur further multicenter investigations toward specific exercise therapy for patients with IPF and other interstitial lung diseases. 
Anne and Nicolino [16] reported that there is a significant increase in maximum inspiratory pressures and the vo2 max by identifying nine studies, most of which included a range of ILD diagnoses. There was a total of 386 participants, including 153 with IPF. Programmes typically used inspiratory muscle training or a combination of inspiratory muscle training and resistive exercise training, whilst some also included education, nutritional advice, stress management and psychosocial support. Programmes ranged from 5 to 12 weeks, with all programmes offering two or more supervised sessions each week.

Nishiyama et al., [17] Reported that there was no statistically significant improvement in $\mathrm{PaO}_{2}$ values in rehabilitated IPF patients between baseline, 4 weeks and 8 weeks. This was supported by researchers who found no improvement in $\mathrm{PaO}_{2}$ values after 10 weeks of PR program. This may be explained by the possibility that PR program does not affect the underlying thickening and fibrosis of the alveolocapillary membrane; the pathologic hallmark of IPF responsible for impaired gas exchange and diffusion defects in those patients although it improves oxygen consumption at muscle level.

\section{Conclusion:}

It was concluded that using of inspiratory muscle trainer is an effective way to increase the maximum inspiratory pressure and slight enhancement of blood gases and that the resistive diaphragmatic breathing has no effect in maximum inspiratory pressure and blood gases in idiopathic pulmonary fibrosis.

\section{Corresponding author:}

Esraa N. Said

Department of Physical Therapy for Cardiovascular/Respiratory Disorder and Geriatrics, Faculty of Physical Therapy, Cairo University, Giza, Egypt.

\section{References}

1- RYERSON C., URBANIA T., RICHELDI L, MOONEY J., LEE J., JONES K., ELICKER B., KOTH L., KING J. and WOLTERS P.: "Prevalence and prognosis of unclassifiable interstitial lung disease". Eur. Respir. J., 42: 750757, 2013.

2- CAYOU C., TOPP F., HILLING L., CAMP P., WILCOX P., KHALIL N., COLLARD H. and GARVEY C.: "Pulmonary rehabilitation improves long-term outcomes in interstitial lung disease": a prospective cohort study. Respir. Med., 108: 203-210, 2014.

3- RYERSON C., URBANIA T., RICHELDI L, MOONEY J., LEE J., JONES K., ELICKER B., KOTH L., KING J. and WOLTERS P.: "Prevalence and prognosis of unclas- sifiable interstitial lung disease". Eur. Respir. J., 42: 750$757,2013$.

4- KULUR A.B., HALEAGRAHARA N., ADHIKARY P. and JEGANATHAN P.S.: "Effect of diaphragmatic breathing on heart rate variability in ischemic heart disease with diabetes". Arq Bras Cardiol., 92 (6): 423-429, 440-427, 457-463, 2011.

5- MELTZER E.B. and NOBLE P.W. : "Idiopathic pulmonary Fibrosis" Orphanet. J. Rare. Dis., 3: 8, 2008.

6- KITAMURA H., ICHINOSE S. and HOSOYA T.: "Inhalation ofinorganic particles as a risk factor for idiopathic pulmonary fibrosis-elemental microanalysis of pulmonary lymph nodes obtained at autopsy cases" Pathol. Res. Pract, 203: 575-85, 2012.

7- HARVER A., MAHLER D.A. and DAUBENSPECK J.A.: "Targeted inspiratory muscle training improves respiratory muscle function and reduces dyspnea in patients with chronic obstructive pulmonary disease". Ann. Intern. Med., 111: 117-24, 2011.

8- GANTER B.G., JAKOB S.M. and TAKALA I.: "Pulmonary capillary pressure" A review. Minerva Anestesiol., 72 (1-2): 21-36, 2006.

9- PATESSIO A., RAMPULLA C. and FRACCHIA C.: "Relationship between the perception of breathlessness and inspiratory resistive loading a report on a clinical trial”. Eur. Respir. J., 7: 587S-91S, 2010.

10- HANSEN J.E. and WASSERMAN K.: "Pathophysiology of activity limitation in patients with interstitial lung disease". Chest, 109: 1566-1576, 2004.

11- JASTRZEBSKI D., KOZIELSKI J. and BANAS' A.: "Quality of life during one-year observation of patients with idiopathic pulmonary fibrosis awaiting lung transplantation”. J. Physiol. Pharmacol., 56: 99-105, 2005.

12- OSAMU N., YASUHIRO K., TOMOKI K., KEISUKE K., KENSUKE K., TOMOYA O., FUMIKO W., SHINICHI A., KOICHI N. and HIROYUKI T.: "Effects of pulmonary rehabilitation in patients with idiopathic pulmonary fibrosis". Respirology, 13: 394-399, 2008.

13- HUPPMANN P., SCZEPANSKI B., BOENSCH M., WINTERKAMP S., SCHÖNHEIT-KENN U., NEUROHR C., BEHR J. and KENN K.: "Effects of in-patient pulmonary rehabilitation in patients with interstitial lung disease". Eur. Respir. J., 42: 444-445, 2012.

14- FLORIAN J., RUBIN A. and MATTIELLO R.: "Impact of pulmonary rehabilitation on quality of life and functional capacity in patients on waiting lists for lung transplantation”. J. Bras Pneumol., 39: 349-56, 2013.

15- IGNACIO A., GAUNAURD P.T. Ph.D., ORLANDO W., CAROL F., CONSTANZA M., MERYL I., LAWRENCE P., DIANA D. and ROBERT M.: "Physical Activity and Quality of Life Improvements of Patients with Idiopathic Pulmonary Fibrosis Completing a Pulmonary Rehabilitation Program”. Respiratory Care, Vol. 59 No. 12, 2014.

16- ANNE H. and NICOLINO A.: "Pulmonary Rehabilitation in Restrictive Thoracic Disorders". Resiratory Care, Vol. 59: 379-390, 2017.

17- NISHIYAMA O., KONDOH Y., KIMURA T. and KATAOKA K.: "Effects of pulmonary rehabilitation in patients with idiopathic pulmonary fibrosis". Respirology, 394-399, 2008. 


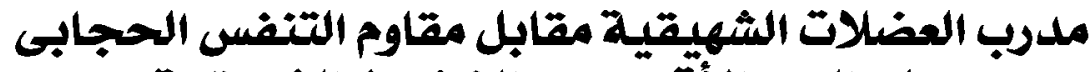

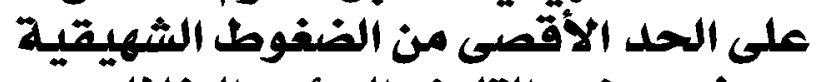

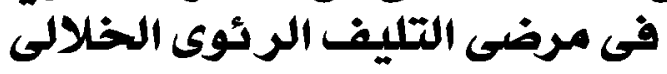

الفرض: للمقارنة بين تأثير مختف المدرب العضلات الثهيق والتفس الحجابى مقاوم على أقصى ضغط الشهيق و غازات الدم فى المرضى الذين يعانون من التليف الرئوى الخلالئ.

$$
\text { طرق التقييم: قياس أقصى ضغط الشهيق وقياس غازات الدم. }
$$

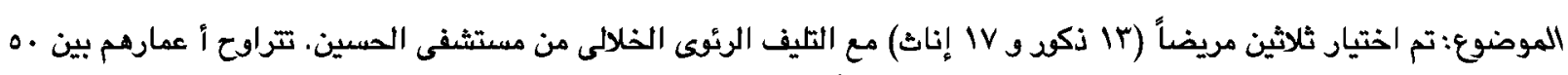

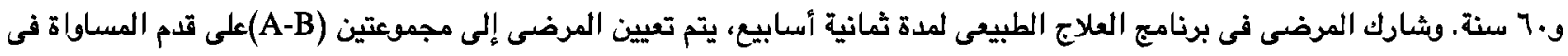

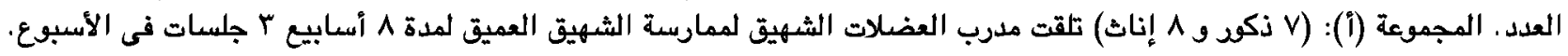

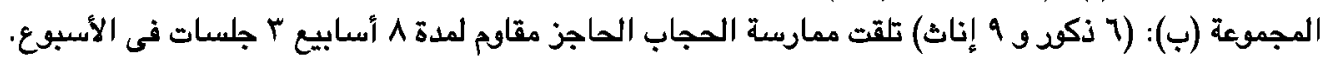

النتائج: أظهرت النتائج أن استخدام مدرب العضلات الشهيق كان أكثر فعالية ومثمرة من ممارسة التنفس الصجابى على ضغط الشهيق الثيق

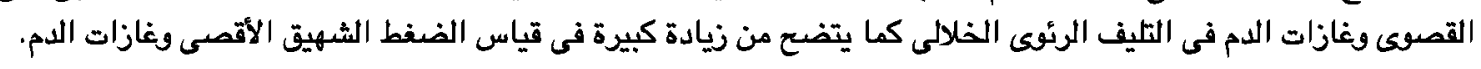

الاستتاج: مدرب العضلات الثهيق هو أكثر فعالية من التفس الحجابى فى زيادة الضغط الشهيق القصوى وغازات الدم فى التليف الرئوى 